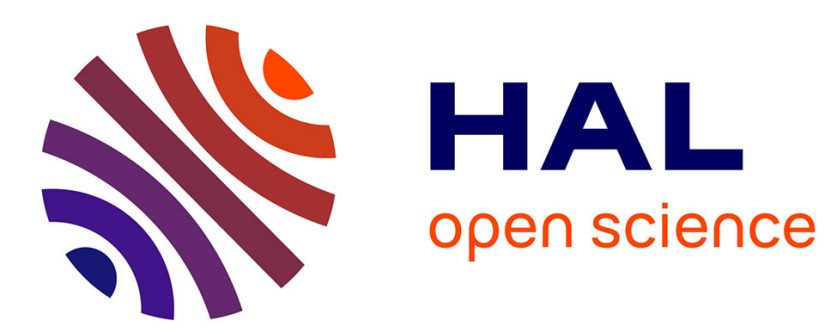

\title{
Additive manufacturing of powder components based on subtractive sintering approach
}

Maricruz Henkel Carrillo, Geuntak Lee, Charles Maniere, Eugene A Olevsky

\section{To cite this version:}

Maricruz Henkel Carrillo, Geuntak Lee, Charles Maniere, Eugene A Olevsky. Additive manufacturing of powder components based on subtractive sintering approach. Rapid Prototyping Journal, 2021, 27 (9), pp.1731-1736. 10.1108/RPJ-01-2021-0006 . hal-03403488

\section{HAL Id: hal-03403488 \\ https://cnrs.hal.science/hal-03403488}

Submitted on 27 Oct 2021

HAL is a multi-disciplinary open access archive for the deposit and dissemination of scientific research documents, whether they are published or not. The documents may come from teaching and research institutions in France or abroad, or from public or private research centers.
L'archive ouverte pluridisciplinaire HAL, est destinée au dépôt et à la diffusion de documents scientifiques de niveau recherche, publiés ou non, émanant des établissements d'enseignement et de recherche français ou étrangers, des laboratoires publics ou privés. 


\title{
Additive manufacturing of powder components based on subtractive sintering approach
}

\author{
Maricruz Henkel Carrillo \\ Department of Mechanical and Aerospace Engineering, University of California San Diego, La Jolla, California, USA \\ Geuntak Lee \\ Department of Mechanical Engineering, San Diego State University, San Diego, California, USA and Department of Mechanical and \\ Aerospace Engineering, University of California San Diego, La Jolla, California, USA \\ Charles Maniere \\ Department of Mechanical Engineering, San Diego State University, San Diego, California, USA, and \\ Eugene A. Olevsky \\ Department of NanoEngineering, University of California San Diego, La Jolla, California, USA and Department of Mechanical \\ Engineering, San Diego State University, San Diego, California, USA
}

\begin{abstract}
Purpose - The purpose of this work is to introduce a novel approach of using additive manufacturing (AM) to produce dense complex ceram ic and metallic parts. Powder 3D printing has been gaining popularity due to its ease of use and versatility. However, powder-based methods such as Selective Laser Melting (SLM) and Sintering (SLS), utilizes high power lasers which generate thermal shock conditions in metals and are not ideal for ceramics due to their high melting temperature. Indirect additive manufacturing methods have been explored to address the above issues but have proven to be wasteful and time-consuming.

Design/methodology/approach - In this work, a novel approach of producing high density net-shaped prototypes using subtractive sintering (SS) and solvent jetting is developed. AM combined with SS (AM-SS) is a process that includes five simple steps. AM-SS can produce repeatable and reliable results as has been shown in this work.

Findings - As a proof-of-concept, a zirconia dental crown with a high density of $97 \%$ is fabricated using this approach. Microstructure and properties of the fabricated components are analyzed.

Originality/value - A major advantage of this method is the ability to efficiently fabricate high density parts using either metal powder and more importantly, ceramic powder which is traditionally difficult to densify using AM. Additionally, any powder particle size (including nano) and shape can be used which is not the case for traditional powder-based 3D printing.
\end{abstract}

Keywords Ceramics, Binder jetting, 3D printing, Additive manufacturing, Sintering, Powder sintering, Solvent jetting, Selective sintering, Net shape, Subtractive sintering, Powder-based printing

\section{Introduction}

The ability of additive manufacturing (AM) technologies to expand from production of prototypic models using polymers to the greater volumes and diverse material systems is critical for continued demand growth for the AM field (Bongomin et al., 2019; Zocca et al., 2015). This transition is highly dependent on having the capacity to print with materials (ceramics, metals and composites) that deliver not only the customizable design accuracy of 3D printing but also the physical and mechanical properties necessary for the application (Stansbury and Idacavage, 2016). Various AM methods have been explored but powder-based methods have

[Rapid Prototyping Journal

DOI 10.1108/RPJ-01-2021-0006] seen significant success compared to others (Jin et al., 2020; Elsayed et al., 2019; Cesarano, 1998).

Powder-based 3D printing is an attractive technology because as opposed to many other 3D printing techniques, it does not require support material (Du et al., 2020; Shirazi et al., 2015).

Powder solidification happens either with a laser or with a binder depending on the technique being used. Laser technologies, such as selective laser melting and selective laser sintering have seen some success in fabricating repeatable and reliable metallic parts for automotive, aerospace and aircraft applications. However, the need for high power lasers generates thermal shock conditions during manufacturing, producing

Corresponding author

Maricruz Henkel Carrillo $\rightarrow$ mhcarrillo@sdsu.edu 
cracks in the fabricated parts. Furthermore, these laser technologies are not suitable for many ceramics due to their high melting temperature (Chang et al., 2017; Maximenko and Olevsky, 2018; Olakanmi et al., 2015). Binder technologies, such as Binder jetting (BJ) and solvent jetting (SJ), use organic binder solution or water-based-ink, respectively (Lee et al., 2020; Chen et al., 2019). Both use binder which means a complex and time-consuming debinding process is necessary, affecting manufacturing time and productivity ( $\mathrm{Au}$ - Lu et al., 2018).

To improve on the limitations mentioned above, various methods of using AM indirectly are being investigated. Indirect AM (I-AM) is a technique where a polymer mold is created and filled in with the desired material (Chen et al., 2014; Montero et al., 2020; Van Hoorick et al., 2015). Manière et al. successfully fabricated net shape parts with high density using this technology via spark plasma sintering (Manière et al., 2019; Eugene Olevsky, 2018). For the present paper, the goal is to achieve high density with only free sintering, not pressure assisted sintering. I-AM casting is a lengthy process that works in a similar way to traditional Investment Casting (Singh et al., 2014) where a polymer scaffold, produced via fused deposition modeling, is casted with a high temperature material (usually a high temperature ceramic), the polymer is then burned out leaving only the ceramic cast. This cast is then used as a sacrificial mold to obtain a sample composed of a second material, usually molten metal (Mun et al., 2014; Mun et al., 2015). This approach has some defect formation issues but in general is successful producing metal parts. However, it cannot be used to make ceramic parts.

When $3 \mathrm{D}$ printing ceramics and metals, sintering is usually necessary after printing to achieve higher densities in the printed part. Naturally, the possibility of using this postprocessing step to fabricate complex shapes has been explored. Selective inhibition sintering (SIS), as the name suggests, is usually described as using sintering inhibitors to sinter only certain parts of the sample. This concept has been used along with powder-based printing of metals (Khoshnevis et al., 2012; Torabi et al., 2014) by depositing sintering inhibitors from the

“ink" cartridge. For ceramics, liquid inhibitors delivered by

inkjet printing are not effective due to the high sintering temperature of ceramics (Khoshnevis et al., 2014). This method can produce complex-shaped parts but with low final sintered density.

In this work, a novel I-AM process called Additive Manufactured Subtractive Sintering (AM-SS) is created. This method uses SS in conjunction with the powder-based 3D printing technique $\mathrm{SJ}$ to print the sacrificial mold and later destroy it during sintering. AM-SS alleviates the limitations faced by the AM techniques described above and issues faced when traditional methods are used for producing high density, complex-shaped parts from ceramics and metals.

\section{Materials and methods}

SJ was used to print the sacrificial mold, followed by Cold Isostatic Pressing (CIP) and SS to produce high density ceramic or metal complex parts needing only free sintering. In AM-SS, instead of printing inhibitors, polymers or expensive molds, a sacrificial mold is printed using a unique material combination that swells and breaks during sintering.

Fully sintered ceramic parts were fabricated in five steps as shown in Figure 1. First, the sacrificial mold is printed using custom printer [Ultimaker 21 with ColorPod modification (Lee et al., 2020)] from a powder mixture comprised of maltodextrin (MD) (Pure Organic brand), sugar (Wholesome brand, powdered) and alumina powder $(-100,1325$ mesh, 99.2\% pure, Materion, USA). This mixture was found to swell and crack after reaching a specific temperature. Second, the inner face of the mold base is sprayed with graphite spray (Blaster) to help with removal and then filled with the article powder (in our case Zirconia Z-pex Smile powder from Tosoh, Inc., Japan). The mold cover is carefully placed as the mold base is slightly tapped to ensure the powder is surrounding any features present in the mold cover. Third, using the standard sample preparation for CIP (CP360, American Isostatic Press), the full assembly is subject to 300-400 MPa pressure to achieve a mold density of at least $60 \%$ before sintering. An individual study on the pressing of the sacrificial mold to find the required pressure is suggested. Due to the nature of isostatic pressing, no shape deformation is expected or observed. Fourth, the CIPed sample is placed in a tube furnace (GSL 1700X, MTI) for sintering. As the sample sinters, the sacrificial mold swells and cracks while the article powders sinter and shrink. Finally, the debris from the mold is removed with a brush and the final sintered sample is attained.

Unlike traditional methods such as investment casting or slip casting, the mold does not require a difficult removal process. In AM-SS, the mold essentially removes itself during sintering which reduces the processing steps from 10-12 (investment casting) to 5. Furthermore, given that the article powder is placed in the mold in its raw form, the possibilities of materials that can be fabricated using this method is more diverse than with any other technique in literature.

One limitation exists with geometry due to the nature of the process. Because the process depends on the swelling, internal channels and structures become difficult to produce yet not impossible. Initial experiments show that internal structures with a small diameter relative to the size of the overall shape can be successfully produced. Additional studies need to be conducted to understand the geometrical limits of AMSS.

Powder processing

The powder used for printing the sacrificial mold to be subtracted during sintering was prepared by mixing alumina

Figure 1 Process of fabricating fully sintered 3D printed part via AM-SS
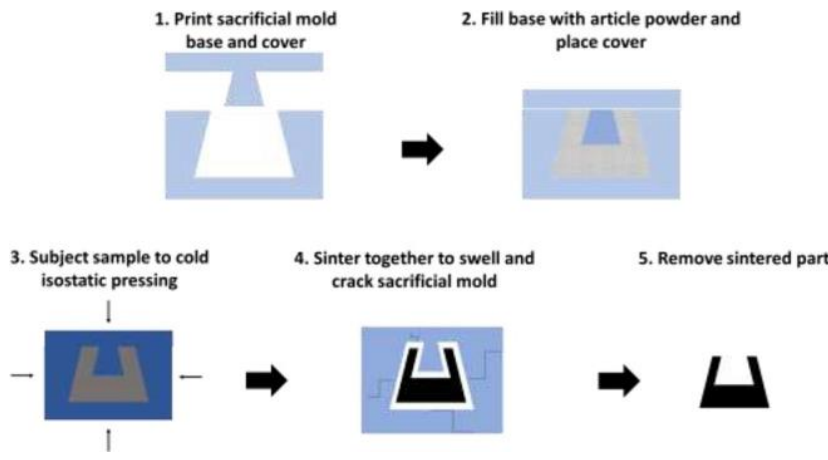
(- 100, 1325 mesh, 99.2\% pure, Materion, USA), maltodextrin (Pure Organic brand) and sugar (Wholesome brand, powdered) powders in a conventional dry mixer (Turbula, GreenMills) for $60 \mathrm{~min}$. Initial tests were made to find the combination of powder concentrations that would provide a printable powder with adequate swelling during sintering but which did not result in distortion of the final sintered part. First, the material combinations were mixed and spread on a Petri dish where they were sprayed with a small amount of the water-based ink. Once a few combinations were found to pass the binding test, they were subject to flowability testing. Flowability of powder was tested by attempting to spread preparation layers in the 3D printer. Finally, the necessary swelling of the material system was confirmed by dilatometry testing (Unitherm model 1161, Anter corporation).

The chosen mixture included $74 \mathrm{Wt} \%$ alumina, $13 \mathrm{Wt} . \%$ maltodextrin and $13 \mathrm{Wt} . \%$ sugar. Example: in $100 \mathrm{~g}$ of powder mixture, $74 \mathrm{~g}$ were alumina, $13 \mathrm{~g}$ were sugar and $13 \mathrm{~g}$ were maltodextrin. In this mixture, the sugar and maltodextrin serve as the binders for printing.

One of the advantages of this method is the use of the article powder in its pure form. In the present work, 3 Mol.\% yttriastabilized nano-zirconia powder (Z-pex Smile, Tosoh, Inc., Japan) was used as the article powder; no further processing was necessary.

\section{$3 D$ printing process}

3D printing of the mold was carried out in a custom-made SJ printer. The water-based ink which is contained in HP 45 InkJet cartridges was composed of $8.3 \mathrm{Vol} \%$ of Isopropyl alcohol, $8.3 \mathrm{Vol} \%$ of diethylene-glycol and $83.4 \mathrm{Vol} \%$ of DI water. Once the preparation layers were spread, the inkjet cartridge sprayed water-based ink in the designated areas as dictated by the CAD model. This process was repeated layer by layer until the printed object was completed. Finally, the printed samples were left in the powder bed at room temperature for a minimum of $4 \mathrm{~h}$ to ensure that samples were dried before using pressurized air to remove loose powder. It is important to note that the powder remaining in the bed can be reused for the following print, leading to a reduction in material waste unlike many other $3 \mathrm{D}$ printing methods.

\section{Sintering}

Sintering was conducted using a conventional tube furnace in the air (GSL-1700X-KS-UL-60, MTI, Richmond, CA). The heating cycle used was: $20^{\circ} \mathrm{C}-200^{\circ} \mathrm{C}$ with $5^{\circ} \mathrm{C} / \mathrm{min}$, holding at $200^{\circ} \mathrm{C}$ for $20 \mathrm{~min}, 200^{\circ} \mathrm{C}$ to $300^{\circ} \mathrm{C}$ with $10^{\circ} \mathrm{C} / \mathrm{min}$, holding at $300^{\circ} \mathrm{C}$ for $60 \mathrm{~min}, 300^{\circ} \mathrm{C}-600^{\circ} \mathrm{C}$ with $5^{\circ} \mathrm{C} / \mathrm{min}$, and holding at $600^{\circ} \mathrm{C}$ for $20 \mathrm{~min}, 600^{\circ} \mathrm{C}-1400^{\circ} \mathrm{C}$ with $5^{\circ} \mathrm{C} / \mathrm{min}, 1400^{\circ} \mathrm{C}-$ $1300^{\circ} \mathrm{C}$ at a rate of $5^{\circ} \mathrm{C}$, holding for $10 \mathrm{~h}$ and cooled down at a rate of $5^{\circ} \mathrm{C} / \mathrm{min}$. The sintering cycle described above was taken from the work of Manière et al. conducted on the Zpex Smile material system (Manière et al., 2020).

\section{Characterization}

The bulk relative densities of the sintered samples were estimated using the Archimedes' immersion method following ASTM standard C373-18. The size of the powder and of the sintered specimen's grains were analyzed using a scanning electron microscopy (SEM), (FEI Quanta 450, USA). Additionally, the printed parts were analyzed using SEM to observe the particle interaction after printing, eventually leading to understanding the sintering inhibition and swelling process.

\section{Results}

\section{Powder characterization}

SEM images of all powders are seen in Figure 2. The average particle size for the alumina powder chosen is $120 \mathrm{~m} \mathrm{~m}$. Micron- sized powder was chosen for the sacrificial mixture because a larger particle size makes sintering more difficult, especially in ceramics, which is desirable for the sacrificial mold. Maltodextrin and sugar powders are also micron size with an average particle size of 40 and $90 \mathrm{~m}$ m, respectively.

The ZPex smile SEM image is seen in Figure 2.

This powder has a particle size range from 10-100 $\mathrm{m} \mathrm{m}$, rounded and is specially made for dental applications. This powder was chosen

to demonstrate the versatility of the developed method given that ceramics, in general, are difficult to fully sinter using powder-based printing.

\section{Sacrificial mold}

The sacrificial mold was solvent jetted using the sacrificial powder mixture made from maltodextrin, sugar and alumina. Using other methods, such as SIS, the size of the part is limited because the whole powder bed is placed in the oven for sintering, thus, the size of the powder bed is limited by the size of the furnace. This is particularly an issue with high temperature materials given that most high temperature furnaces are smaller in size.

There are three aspects of the sacrificial mold that contribute to easy part removal; sintering inhibition, swelling and densification behaviors of the mold and article powders. As seen in Figure 3, the water-based ink that activates the binder creates a large neck (indicated by the arrows) between the alumina particles. These necks push the alumina particles far away from each other, sometimes by a relatively large distance.

Figure 2 SEM Images of powders: alumina, sugar, maltodextrin and zirconia (clockwise)
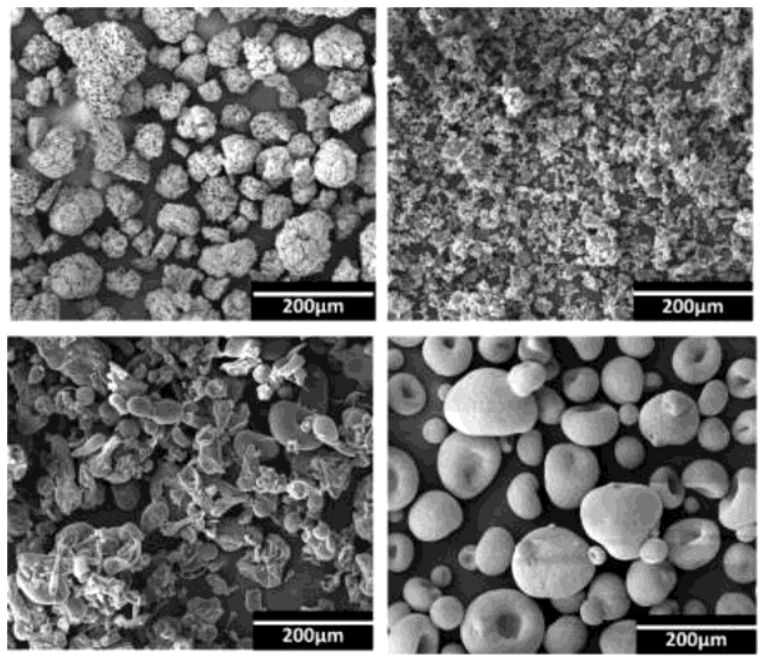
Figure 3 Binder neck formation between alumina powder particles formed during solvent jetting

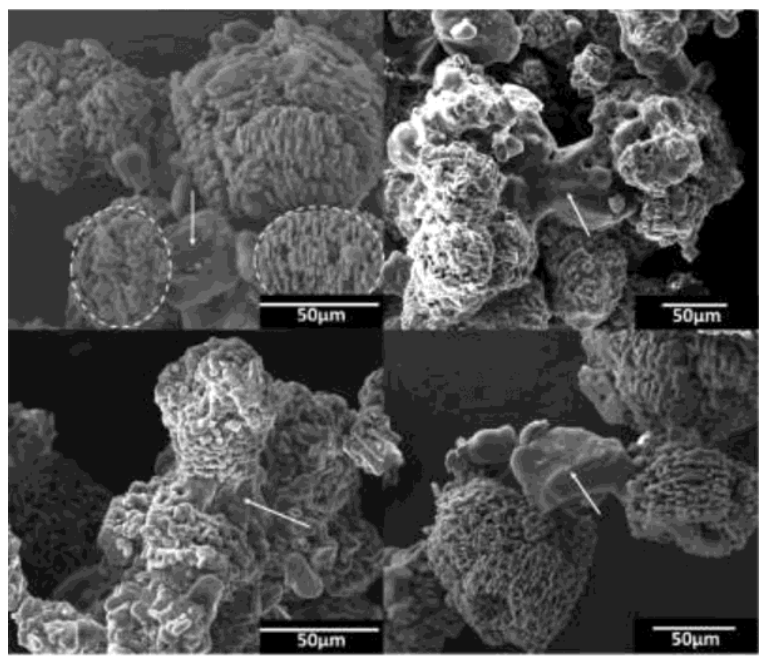

Note: Dashed lines encircle the alumina particles and the arrows point out the binder neck

The coalescence of particles during sintering becomes difficult as the distance between particles increases and, in this way, sintering is inhibited in the sacrificial mold.

The swelling phenomenon can be explained by analyzing the SEM images of the CIPed green sample and taking normal outgassing of binders into account. Because both sugar and maltodextrin are carbon-based polymers and the sintering conditions are in air, the binders will react with oxygen to create carbon dioxide, a gas, that needs to be released After pressing, the open space available for the binder to escape is reduced significantly, therefore, when the binder is decomposing, it releases a significant amount of gas too quickly and pushes against the sample itself and makes it swell. From the DSC

Figure 4 DSC plots of binders; maltodextrin (top) and sugar (bottom) showing the additional thermal expansion of each binder component with the arrow once decomposition is completed

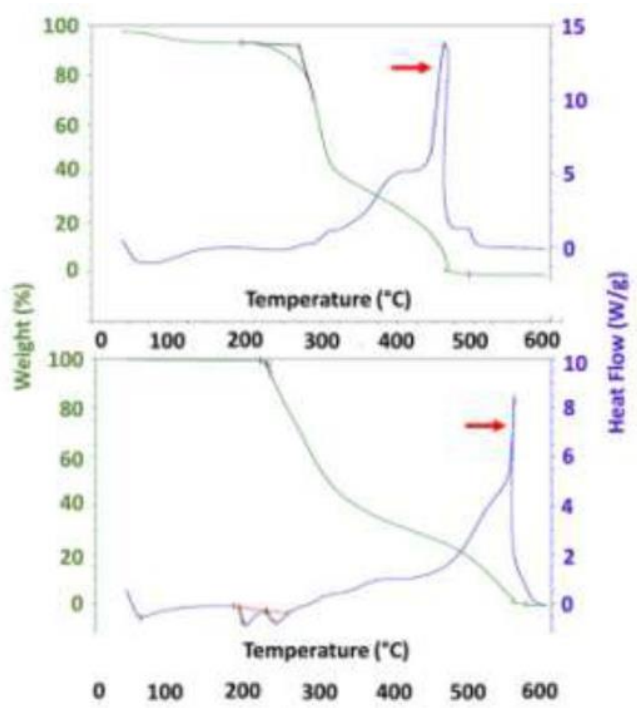

(SDT Q600, TA Instruments) for both binders (Figure 4), they both begin to decompose at around $200^{\circ} \mathrm{C}$ as shown by the Wt.\% loss curve. Sugar and maltodextrin produce the explosive swelling at around $480^{\circ} \mathrm{C}$ and $580^{\circ} \mathrm{C}$, respectively, as shown by the arrows. By $600^{\circ} \mathrm{C}$ in the cycle, both binders reach $0 \%$ weight, and it can therefore be assumed both binders are removed by the end of the cycle.

Finally, the general densification behavior during sintering of the article powders and the sacrificial mold explains how their behavior aids in the removal of the target part. As the sintering cycle progresses, the article powder density increases exponentially while the sacrificial mold density decreases. Additionally, alumina has a higher sintering temperature than zirconia giving the sacrificial mold no opportunity to densify even at the highest temperature of the sintering cycle.

Attention must also be given to the fact that using the present method, the final part will be made up of only the article powder without the need for a long debinding process. Debinding is complex and time-consuming; sometimes taking a few days and multiple sintering cycles. Also, after debinding, some binder elements may remain in the specimen's volume and generate gas pressure during sintering, which impedes the sintering process resulting in low relative density and an adverse effect on the mechanical properties of the final products.

\section{Microstructure analysis of dental crown}

As a proof-of-concept, a high-density zirconia dental crown was fabricated by AM-SS. The relative density of the manufactured dental crown is $-97 \%$ which cannot be obtained by traditional $\mathrm{SJ}$ approach. In powder metallurgy, a density in this range may not be considered high density but for ceramicists using free sintering, this result is among the highest reported.

The final density of $97 \%$ was obtained using the Archimedes method and confirmed with SEM imaging. Grain size was found to be small $(<40 \mathrm{~nm})$ as in Figure 5. Small grain sizes are desired for improving mechanical and optical

properties. The level of translucency was tested by using a laser as demonstrated in Figure 6(d). This material is highly translucent indicating the fabricated crown has a high density and a small average grain size (Carrabba et al., 2017)

\section{Conclusions}

A high-density ceramic part was fabricated using the novel technique of AM-SS. A traditional powder-based printing process produces 3D shape components with low green density, which prevents the densification during the follow-up sintering. Furthermore, the article powders used in printing usually have binders inside their volume, therefore pressureassisted consolidation technologies like the CIP applied in this work cannot be applied because the binder inside would generate shape distortion or cracks during the sintering process. In the present work, the article material (Zirconia) can include pure powders without binders; hence the pressure can be applied without shape distortion or crack generation. By pressing the sacrificial mold and the article powder at the same time, the green density of the green part can be increased to a level higher than $50 \%$, so that it is ready to be fully consolidated during sintering and can achieve full density under the optimum temperature settings.

In addition, the AM-SS approach enables the usage of nanosized powders, which are typically not utilized in powder-based 
Figure 5 Microstructure of zirconia dental crown

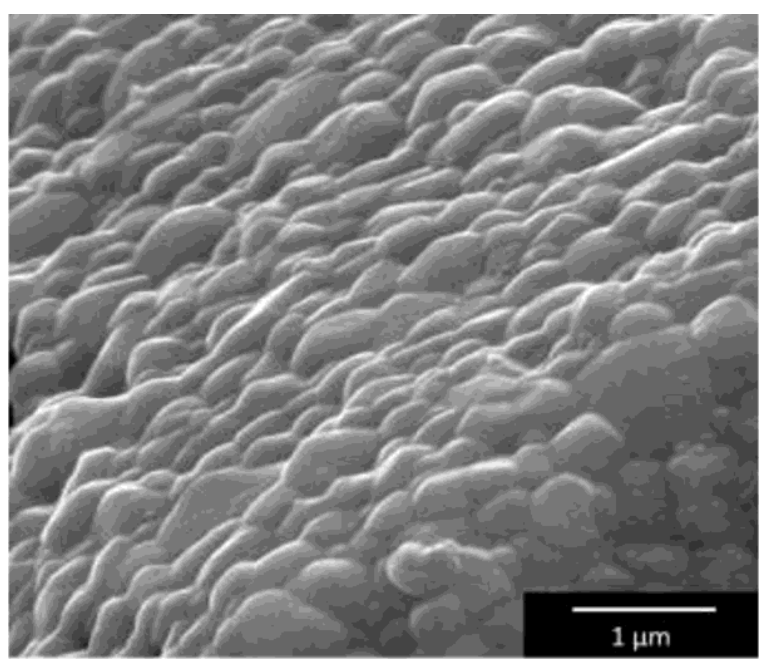

Figure 6 Final dental crown (a) sacrificial mold, (b) top of sintered dental crown, (c) bottom of sintered dental crown and (d) translucency test demonstrating small grain size
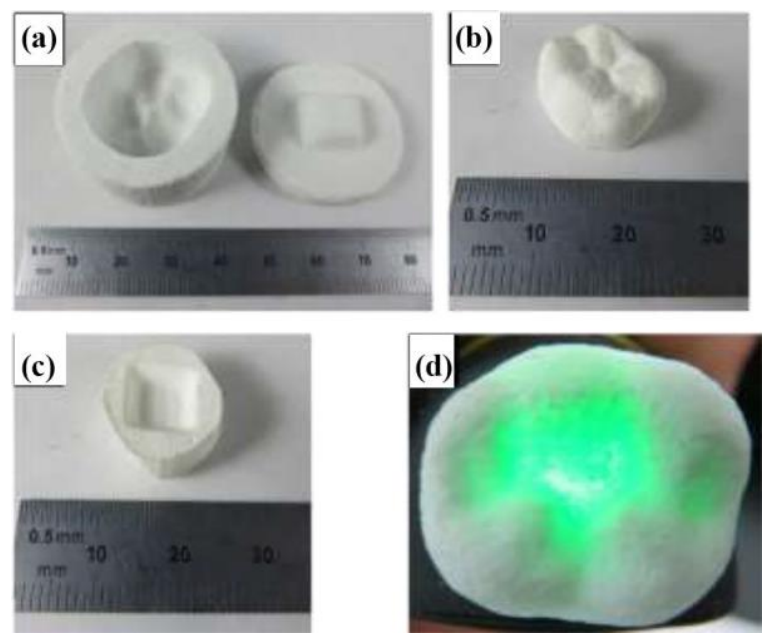

printing due to their limited flowability. The use of nano-sized powders is desired due to its initial small grain size and sinterability. Small grain sizes are desirable because they are known to provide higher mechanical strengths and some translucent optical properties. Furthermore, small particle sizes are more sinterable than micron sized powders. Using nanosized powders renders a low sintering temperature and small average grain sizes of the final complex parts, which was not achievable by powder-based $3 \mathrm{D}$ printing in the past.

There is one more advantage to AM-SS regarding the productivity. This method enables the avoidance of the use of the pressure-assisted sintering, which otherwise generally becomes a roadblock to mass production. Using the five-step AM-SS process described in the present work, many parts with different or same complex shapes can be obtained in a straightforward manner with no need for curing, debinding or infiltration which are generally used to increase density of final parts produced via powder-based printing.
Overall, the present work demonstrated the potential of AM-SS in producing high density complex-shaped parts from any material with free sintering and without the need of a long debinding process. Further studies will be conducted to include a shape prediction tool to make this method applicable to more industries.

\section{References}

Au-Lu, R., Au-Miller, D.J., Au-Du Frane, W.L., AuChandrasekaran, S., Au-Landingham, R.L.,

Au-Worsley, M.A. and Au-Kuntz, J.D. (2018), "Negative additive manufacturing of complex shaped boron carbides", JoVE, e58438.

Bongomin, O., Gilibrays, G., Oyondi Nganyi, E., Musinguzi, A. and Omara, T. (2019), "Exponential disruptive technologies and the required skills of industry 4.0: a review".

Carrabba, M., Keeling, A.J., Aziz, A., Vichi, A., Fabian Fonzar, R., Wood, D. and Ferrari, M. (2017), “Translucent zirconia in the ceramic scenario for monolithic restorations: a flexural strength and translucency comparison test", Journal of Dentistry, Vol. 60, pp. 70-76.

Cesarano, J. (1998), "A review of robocasting technology", MRS Proceedings, Vol. 542, p. 133.

Chang, S., Li, L., Lu, L. and Fuh, J.Y.H. (2017), "Selective laser sintering of porous silica enabled by carbon additive", Materials (Materials), Vol. 10 No. 11, p. 1313.

Chen, C.-H., Liu, J.M., Chua, C.-K., Chou, S.-M., Shyu, V.B. and Chen, J.-P. (2014), "Cartilage tissue engineering with silk fibroin scaffolds fabricated by indirect additive manufacturing technology", Materials, Vol. 7 No. 3.

Chen, Z., Li, Z., Li, J., Liu, C., Lao, C., Fu, Y., Liu, C., Li, Y., Wang, P. and He, Y. (2019), "3D printing of ceramics: a review", Journal of the European Ceramic Society, Vol. 39 No. 4, pp. 661-687.

Du, W., Ren, X., Pei, Z. and Ma, C. (2020), "Ceramic binder jetting additive manufacturing: a literature review on density", Journal of Manufacturing Science and Engineering, Vol. 142 No. 4.

Elsayed, H., Chmielarz, A., Potoczek, M., Fey, T. and Colombo, P. (2019), "Direct ink writing of three dimensional Ti2AlC porous structures", Additive Manufacturing, Vol. 28.

Eugene Olevsky, D.D. (2018), Field-Assisted Sintering, Springer International Publishing, pp. 89-191.

Jin, H., Yang, Z., Li, H., Jia, D. and Zhou, Y. (2020), "Fabrication of Si2N2O ceramic foam by combination of direct ink writing and biological foaming techniques", Advanced Engineering Materials, Vol. 22 No. 4, p. 1901541.

Khoshnevis, B., Yoozbashizadeh, M. and Chen, Y. (2012), "Metallic part fabrication using selective inhibition sintering (SIS)", Rapid Prototyping Journal, Vol. 18 No. 2, pp. 144-153.

Khoshnevis, B., Zhang, J., Fateri, M. and Xiao, Z. (2014), "Ceramics $3 \mathrm{~d}$ printing by selective inhibition sintering".

Lee, G., Carrillo, M., Mckittrick, J., Martin, D.G. and Olevsky, E.A. (2020), "Fabrication of ceramic bone scaffolds by solvent jetting 3D printing and sintering: towards loadbearing applications", Additive Manufacturing, Vol. 33, p. 101107. 
Manière, C., Torresani, E. and Olevsky, E.A. (2019), "Simultaneous spark plasma sintering of multiple complex shapes”, Materials, Vol. 12 No. 4.

Manière, C., Lee, G., Mckittrick, J., Chan, S. and Olevsky, E.A. (2020), "Modeling zirconia sintering trajectory for obtaining translucent submicronic ceramics for dental implant applications", Acta Materialia, Vol. 188, pp. 101-107.

Maximenko, A.L. and Olevsky, E.A. (2018), "Pore filling during selective laser melting - assisted additive manufacturing of composites", Scripta Materialia, Vol. 149, pp. 75-78.

Montero, J., Vitale, P., Weber, S., Bleckmann, M. and Paetzold, K. (2020), "Indirect additive manufacturing of resin components using polyvinyl alcohol sacrificial moulds", Procedia CIRP, Vol. 91, pp. 388-395.

Mun, J., Ju, J. and Thurman, J. (2014), "Indirect additive manufacturing based casting (I AM casting) of a lattice structure".

Mun, J., Yun, B.-G., Ju, J. and Chang, B.-M. (2015), "Indirect additive manufacturing based casting of a periodic 3D cellular metal - flow simulation of molten aluminum alloy", Journal of Manufacturing Processes, Vol. 17, pp. 28-40.

Olakanmi, E.O., Cochrane, R.F. and Dalgarno, K.W. (2015), "A review on selective laser sintering/melting (SLS/SLM) of aluminium alloy powders: processing, microstructure, and properties", Progress in Materials Science, Vol. 74, pp. 401-477.

Shirazi, S.F.S., Gharehkhani, S., Mehrali, M., Yarmand, H., Metselaar, H.S.C., Adib Kadri, N. and Osman, N.A.A. (2015),
"A review on powder-based additive manufacturing for tissue engineering: selective laser sintering and inkjet 3D printing", Science and Technology of Advanced Materials, Vol. 16 No. 3, p. 33502 .

Singh, R., Singh, S. and Singh, G. (2014), "Dimensional accuracy comparison of investment castings prepared with wax and ABS patterns for bio-medical application", Procedia Materials Science, Vol. 6, pp. 851-858.

Stansbury, J.W. and Idacavage, M.J. (2016), “3D printing with polymers: challenges among expanding options and opportunities", Dental Materials, Vol. 32 No. 1, pp. 54-64.

Torabi, P., Petros, M. and Khoshnevis, B. (2014), "Selective inhibition sintering: the process for consumer metal additive manufacturing", 3D Printing and Additive Manufacturing, Vol. 1 No. 3, pp. 152-155.

van Hoorick, J., Declercq, H., DE Muynck, A., Houben, A., van Hoorebeke, L., Cornelissen, R., van Erps, J., Thienpont, H., Dubruel, P. and van Vlierberghe, S. (2015), "Indirect additive manufacturing as an elegant tool for the production of self-supporting low density gelatin scaffolds", J Mater Sci Mater Med, Vol. 26, p. 247.

Zocca, A., Colombo, P., Gomes, C.M. and Günster, J. (2015), "Additive manufacturing of ceramics: issues, potentialities, and opportunities", Journal of the American Ceramic Society, Vol. 98 No. 7, pp. 1983-2001. 